\title{
Influence of MHD Hybrid Ferrofluid Flow on Exponentially Stretching/Shrinking Surface with Heat Source/Sink under Stagnation Point Region
}

\author{
Nur Syazana Anuar $1, * \mathbb{D}$, Norfifah Bachok ${ }^{2,3}$ and Ioan Pop ${ }^{4}$ \\ 1 Faculty of Computer and Mathematical Sciences, Universiti Teknologi MARA, Shah Alam 40450, \\ Selangor, Malaysia \\ 2 Department of Mathematics \& Statistics, Faculty of Science, Universiti Putra Malaysia, Serdang 43400, \\ Selangor, Malaysia; norfifah@upm.edu.my \\ 3 Institute for Mathematical Research, Universiti Putra Malaysia, Serdang 43400, Selangor, Malaysia \\ 4 Department of Mathematics, Babes-Bolyai University, 400084 Cluj-Napoca, Romania; ipop@math.ubbcluj.ro \\ * Correspondence: nursyazana931@tmsk.uitm.edu.my
}

Citation: Anuar, N.S.; Bachok, N.; Pop, I. Influence of MHD Hybrid Ferrofluid Flow on Exponentially Stretching/Shrinking Surface with Heat Source/Sink under Stagnation Point Region. Mathematics 2021, 9, 2932. https://doi.org/10.3390/ math9222932

Academic Editors:

Araceli Queiruga-Dios, Maria Jesus Santos, Fatih Yilmaz, Deolinda M. L. Dias Rasteiro, Jesús

Martín Vaquero and Víctor Gayoso Martínez

Received: 23 September 2021

Accepted: 21 October 2021

Published: 17 November 2021

Publisher's Note: MDPI stays neutral with regard to jurisdictional claims in published maps and institutional affiliations.

Copyright: (c) 2021 by the authors. Licensee MDPI, Basel, Switzerland. This article is an open access article distributed under the terms and conditions of the Creative Commons Attribution (CC BY) license (https:// creativecommons.org/licenses/by/ $4.0 /)$.

\begin{abstract}
The numerical investigations of hybrid ferrofluid flow with magnetohydrodynamic (MHD) and heat source/sink effects are examined in this research. The sheet is assumed to stretch or shrink exponentially near the stagnation region. Two dissimilar magnetic nanoparticles, namely cobalt ferrite, $\mathrm{CoFe}_{2} \mathrm{O}_{4}$ and magnetite, $\mathrm{Fe}_{3} \mathrm{O}_{4}$, are considered with water as a based fluid. Utilizing the suitable similarity transformation, the governing equations are reduced to an ordinary differential equation (ODE). The converted ODEs are numerically solved with the aid of bvp4c solver from Matlab. The influences of varied parameters on velocity profile, skin friction coefficient, temperature profile and local Nusselt number are demonstrated graphically. The analysis evident the occurrence of non-unique solution for a shrinking sheet and it is confirmed from the analysis of stability that only the first solution is the stable solution. It is also found that for a stronger heat source, heat absorption is likely to happen at the sheet. Further, hybrid ferrofluid intensifies the heat transfer rate compared to ferrofluid. Moreover, the boundary layer separation is bound to happen faster with an increment of magnetic parameter, while it delays when $\mathrm{CoFe}_{2} \mathrm{O}_{4}$ nanoparticle volume fraction increases.
\end{abstract}

Keywords: hybrid ferrofluid; dual solution; exponentially stretching/shrinking; stability analysis; heat source/sink

\section{Introduction}

Ferrofluids or magnetic colloids are made by disseminating magnetic nanoparticles like cobalt ferrite $\mathrm{CoFe}_{2} \mathrm{O}_{4}$, hematite $\mathrm{Fe}_{2} \mathrm{O}_{3}$, magnetite $\mathrm{Fe}_{3} \mathrm{O}_{4}$ and many other nanometersized particles containing iron in the base fluid [1]; as a result, these particles have a dipolar interaction energy and magnetic moment in the base fluid. Ferrofluids have various biomedicine and engineering applications specifically in drug delivery [2], chemical activity monitoring in the human brain in real-time, destruction of tumors and toxin elimination from the body [3], rotary seals in computer hard drives and other rotating shaft motors [4]. For these reasons, many researchers [5-8] have focused their investigation on ferrofluids. Usually, nanofluid comprises only one nanoparticle whereas the hybrid nanofluid comprises two distinct nanoparticles disseminated in a base fluid [9]. Through the combination of two dissimilar nanomaterials, hybrid nanofluids are created to improve their thermal and rheological properties [10]. Suresh et al. [11] presented an experimental investigation using a two-step method (thermomechanical method) to synthesize hybrid $\left(\mathrm{Al}_{2} \mathrm{O}_{3}-\mathrm{Cu}\right.$ /water) nanofluid. The outcomes demonstrated that the prepared hybrid nanofluid for a concentration of $2 \%$ nanoparticle volume fraction increase its thermal conductivity by $12.11 \%$. In another experimental investigation, Madhesh and 
Kalaiselvam [12] examined the properties of $\mathrm{Cu}-\mathrm{TiO}_{2} /$ water nanofluid in a cooling system, while Esfe et al. [13] scrutinized the thermal conductivity of the hybrid (Ag-MgO) nanofluid and discovered that its conductivity rises with augmentation of nanoparticles concentration. Chu et al. [14] examined the thermal performance and flow characteristics of hybridized nanofluid (MWCNT- $\mathrm{Fe}_{3} \mathrm{O}_{2}$ /water) in a cavity. The flow features of hybrid ferrofluids $\left(\mathrm{Fe}_{3} \mathrm{O}_{4}-\mathrm{CoFe}_{2} \mathrm{O}_{4}\right)$ with water-ethylene glycol mixture (50-50\%) as a based fluid in the thin film flow were investigated by Kumar et al. [15] and they revealed that hybrid ferrofluid offers a higher rate of heat transfer than that of ferrofluid. Researchers from all over the world have been drawn to hybrid nanofluids because of their exceptional heat augmentation behavior, which gives fine control over heat transfer in numerous industries. Due to that, several experimental and theoretical investigations on hybrid nanofluid have been published widely such as in references [16-18]. Therefore, the aim of developing hybrid ferrofluid is therefore to manage heat transfer efficiently in the flow field.

It seems that magnetohydrodynamic (MHD), heat source (generation) and heat sink (absorption) effects are crucial in monitoring the heat transfer in the production of quality products as it depends on the heat monitoring factor. This is also mainly due to the reason that MHD terms extremely appeared in various engineering and industrial processes like MHD generator, cancer therapy, MHD power generation, nuclear reactor, etc. [19]. The influences of heat source and sink are also important in cooling problems associated with nuclear reactions, combustion processes, and magnetized utilization in neurobiology to learn brain function [20]. In view of the increasing importance of MHD and heat source/sink, a lot of work has been carried out to investigate these effects in boundary layer flow. For instance, the simultaneous impact of MHD, heat source/sink and suction instigated by a shrinking sheet can be observed in the work of Bhattacharyya [21] and observed that increasing heat sink parameters cause the heat transfer to enhance. Further, Gorla et al. [22] explored the same effects in a hybrid nanofluid-filled porous cavity. Recently, Armaghani et al. [23] scrutinized the generation/absorption of heat and MHD in their investigation of hybrid nanofluid in an L-shaped cavity. They deduced that using the highest number of sink power results in the best heat transfer. Furthermore, the studies on MHD flow and heat source/sink by means of various physical configurations have been conducted by Jamaludin et al. [24] and Reddy et al. [25].

Nowadays, the existence of non-unique solutions has gained the attention of modern researchers. In some boundary layer flow problems, non-unique solutions have generally been found for linear shrinking sheet cases. For instance, non-unique solutions have been observed by Wang [26], Bachok et al. [27], Kamal et al. [28] and Anuar and Bachok [29], among others for the stagnation flow problem. Meanwhile, Bhattacharyya and Vajravelu [30], Bachok et al. [31] and Anuar et al. [32] have observed the occurrence of non-unique solutions in their investigation of stagnation flow when the sheet is shrunk exponentially. They conclude that the domain of similarity solution to existing is larger for the stagnation flow in the exponential case rather than in the linear case. However, there also exist some situations where non-unique solutions happen to exist for both cases, i.e., stretching and shrinking (see for instance the research carried out by Lund et al. [33] and Waini et al. [34]). With regards to the existence of more than one solution, a stability analysis on the solutions obtained has been performed by some researchers. This kind of analysis is important in order to avoid any misleading interpretation of flow. Some important investigations concerning the stability analysis on the solutions of boundary layer flow problem were made by Merkin [35], Weidman et al. [36], Harris et al. [37] and more recently by Anuar et al. [38], Mustafa et al. [39] and Aladdin et al. [40,41], among others. It has been observed that the second solution has always been unstable and therefore unobtainable in practice, while the other solution is stable.

Owing to the nonlinearity of equations that describe most engineering and science phenomena, many authors used numerical methods such as finite element methods [22,23], shooting method $[6,15,30]$ and bvp4c solver $[18,24,34,40]$ to solve the governing equations. For the present problem, in solving the system of nonlinear equations, Matlab bvp4c 
built-in code is employed. The Matlab bvp4c solver is a residual control-based adaptive mesh solver. The algorithm is based on the Runge-Kutta improved formulas that have interpolation capability [42]. It has been used successfully by many researchers to solve boundary value problems from different models in science and engineering. This method was found to be robust and consistent, showing superiority over the shooting method.

The goal of this investigation is to scrutinize the heat generation/absorption of MHD hybrid ferrofluid $\left(\mathrm{CoFe}_{2} \mathrm{O}_{4}-\mathrm{Fe}_{3} \mathrm{O}_{4}\right.$ / water) flow instigated by an exponentially deformable sheet. In the light of the previous literature survey, it is worthy to mention that no attempt has been made on this kind of flow problem yet. Here, the similarity variable is used to convert the governing equations into an ODE which later be solved numerically using bvp4c (Matlab's built-in function). The computed results for relevant parameters concerning local Nusselt number and skin friction coefficient, together with temperature profile and velocity profile, are visualized graphically and elaborated in detail. Further, the occurrence of two solutions motivates us to identify the stable and unstable solutions by performing the stability analysis. In addition, this theoretical study would help engineers who are experimentally working on hybrid ferrofluids, and the findings are expected to reduce the cost of future experiments.

\section{Problem Formulation}

\subsection{Mathematical Framework}

The two-dimensional and steady flow of MHD hybrid ferrofluid past a deformable sheet are investigated and portrayed in Figure 1. The $x$-axis is selected along the direction of the horizontal surface while $y$-axis is perpendicular to it. The surface of the sheet is shrunk or stretched with exponential velocity $u_{w}(x)=a \exp (x / L)$ given that $a$ and $L$ are the positive constant and characteristic length, respectively. As shown in Figure 1, magnetic $B$ and heat generation/absorption $Q(x)$ are applied parallel to the $y$-axis and will be defined later. Distant from the horizontal surface, the flow is kept at constant temperature $T_{\infty}$ and free stream velocity $u_{e}(x)=b \exp (x / L)$; here $b$ is the positive constant. Further, the surface temperature is assumed to vary as prescribed exponential function and denoted by $T_{w}=T_{\infty}+T_{0} \exp \left(\frac{x}{2 L}\right)$ where $T_{0}$ is the rate at which the temperature rises along the sheet is measured.

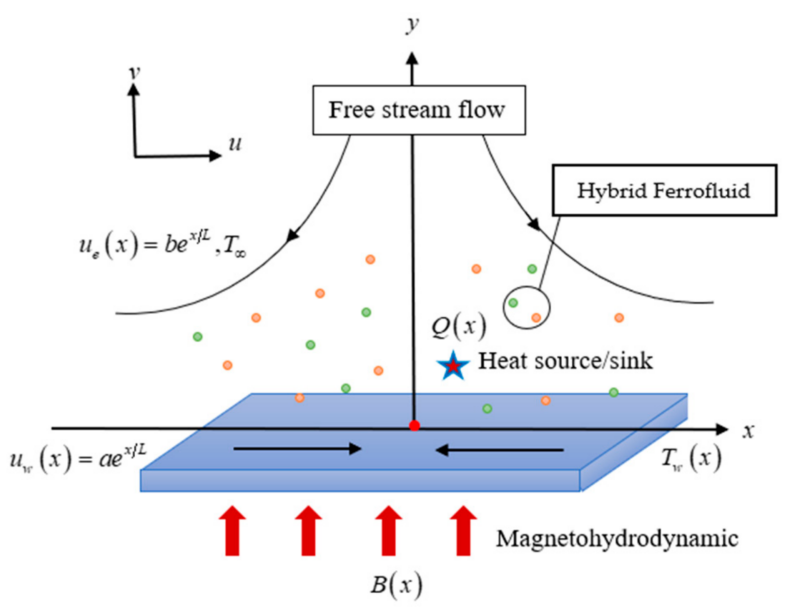

Figure 1. Flow model of shrinking sheet and its coordinate system.

Following the mathematical formulation and idea proposed by Kumar et al. [15], Wang [26] and Kamal et al. [28], the governing partial differential equations are denoted as:

$$
\frac{\partial u}{\partial x}+\frac{\partial v}{\partial y}=0
$$




$$
\begin{aligned}
& u \frac{\partial u}{\partial x}+v \frac{\partial u}{\partial y}=u_{e} \frac{d u_{e}}{d x}+\frac{\mu_{h f}}{\rho_{h f}} \frac{\partial^{2} u}{\partial y^{2}}-\frac{\sigma_{h f}}{\rho_{h f}} B^{2}\left(u-u_{e}\right) \\
& u \frac{\partial T}{\partial x}+v \frac{\partial T}{\partial y}=\frac{k_{h f}}{\left(\rho C_{p}\right)_{h f}} \frac{\partial^{2} T}{\partial y^{2}}+\frac{Q(x)}{\left(\rho C_{p}\right)_{h f}}\left(T-T_{\infty}\right)
\end{aligned}
$$

$(u, v)$ in the above equation indicates the velocity component in the $(x, y)$ direction and $T$ refers to the fluid's temperature. Further, $\mu$ denotes the dynamic viscosity, $\rho$ refers to the density, $\sigma$ and $k$ are the electrical and thermal conductivity, respectively, and $C_{p}$ is the specific heat where the subscript ' $h f^{\prime}$ 'signifies the hybrid ferrofluid.

The relevant boundary conditions are given as (Bachok et al. [27]):

$$
T=T_{w}(x), \quad v=0, \quad u=u_{w}(x) \quad \text { at } \quad y=0 ; \quad T \rightarrow T_{\infty}, \quad u \rightarrow u_{e}(x) \quad \text { as } \quad y \rightarrow \infty
$$

\subsection{Correlation Used for Hybrid Ferrofluid}

The thermophysical properties for the hybrid ferrofluid are employed from the work of Takabi and Salehi [9] and Gorla et al. [22] (see Table 1). The first and second nanoparticles are denoted by subscripts " 1 " and " 2 " in the table. Further, $\varphi$ is the summation of the volume concentration of two dissimilar kinds of nanoparticles, i.e., $\varphi=\varphi_{1}+\varphi_{2}$.

Table 1. Thermophysical traits of hybrid ferrofluid.

\begin{tabular}{cc}
\hline Properties & Hybrid Ferrofluid \\
\hline Density & $\rho_{h f}=(1-\varphi) \rho_{f}+\varphi_{1} \rho_{1}+\varphi_{2} \rho_{2}$ \\
Thermal conductivity & $\frac{k_{h f}}{k_{f}}=\frac{\left(\left(\varphi_{1} k_{1}+\varphi_{2} k_{2}\right) / \varphi\right)+2 k_{f}+2\left(\varphi_{1} k_{1}+\varphi_{2} k_{2}\right)-2 \varphi k_{f}}{\left(\left(\varphi_{1} k_{1}+\varphi_{2} k_{2}\right) / \varphi\right)+2 k_{f}-\left(\varphi_{1} k_{1}+\varphi_{2} k_{2}\right)+\varphi k_{f}}$ \\
Heat capacity & $\left(\rho C_{p}\right)_{h f}=(1-\varphi)\left(\rho C_{p}\right)_{f}+\varphi_{1}\left(\rho C_{p}\right)_{1}+\varphi_{2}\left(\rho C_{p}\right)_{2}$ \\
Dynamic viscosity & $\mu_{h f}=\mu_{f} /(1-\varphi)^{2.5}$ \\
Electrical conductivity & $\frac{\sigma_{h f}}{\sigma_{f}}=1+\frac{3\left(\left(\left(\varphi_{1} \sigma_{1}+\varphi_{2} \sigma_{2}\right) / \sigma_{f}\right)-\varphi\right)}{\left(\left(\left(\varphi_{1} \sigma_{1}+\varphi_{2} \sigma_{2}\right) /\left(\varphi \sigma_{f}\right)\right)+2\right)-\left(\left(\left(\varphi_{1} \sigma_{1}+\varphi_{2} \sigma_{2}\right) / \sigma_{f}\right)-\varphi\right)}$ \\
\hline
\end{tabular}

It should be emphasized that the desired hybrid ferrofluid is formed by suspending $1 \%$ of Iron Oxide $\left(\mathrm{Fe}_{3} \mathrm{O}_{4}\right)$ nanoparticle into the base fluid (water). Then, Cobalt Iron Oxide $\left(\mathrm{CoFe}_{2} \mathrm{O}_{4}\right)$ nanoparticle is added into the $\mathrm{Fe}_{3} \mathrm{O}_{4}$ / water nanofluid and eventually formed a hybrid ferrofluid. In addition, the volume fraction of $\mathrm{CoFe}_{2} \mathrm{O}_{4}$ nanoparticles is fluctuated from 0 to $2 \%$. Therefore, in this study, the first nanoparticle is denoted by $\mathrm{Fe}_{3} \mathrm{O}_{4}$ while the second nanoparticle refers to $\mathrm{CoFe}_{2} \mathrm{O}_{4}$. The physical characteristics of the base fluid and the nanosized particles are shown in Table 2 (Abbas and Sheikh [7], Oztop and Abu-Nada [43], Sheikholeslami et al. [44], Tlili et al. [45]).

Table 2. Thermophysical properties of nanoparticle and base fluid.

\begin{tabular}{ccccc}
\hline & \multicolumn{4}{c}{ Physical Properties } \\
\cline { 2 - 5 } & $\boldsymbol{C}_{\boldsymbol{p}}\left(\boldsymbol{J} \cdot \mathbf{k g}^{-1} \cdot \boldsymbol{K}^{-1}\right)$ & $\boldsymbol{\rho}\left(\mathbf{k g} \cdot \mathbf{m}^{-3}\right)$ & $\boldsymbol{k}\left(\boldsymbol{W} \cdot \boldsymbol{m}^{-1} \cdot \boldsymbol{K}^{-1}\right)$ & $\sigma\left(\mathrm{S} \cdot \boldsymbol{m}^{-1}\right)$ \\
\hline water, $\mathrm{H}_{2} \mathrm{O}$ & 4179 & 997.1 & 0.613 & 0.05 \\
\hline Magnetic nanoparticles & & & & \\
Magnetite, $\mathrm{Fe}_{3} \mathrm{O}_{4}$ & 670 & 5180 & 9.7 & $0.74 \times 10^{6}$ \\
Cobalt Ferrite, $\mathrm{CoFe}_{2} \mathrm{O}_{4}$ & 700 & 4907 & 3.7 & $1.1 \times 10^{7}$ \\
\hline Non-magnetic nanoparticles & & & & \\
Copper, $\mathrm{Cu}$ & 385 & 8933 & 401 & $5.96 \times 10^{7}$ \\
Titania, $\mathrm{TiO}_{2}$ & 686.2 & 4250 & 8.9538 & $1 \times 10^{-12}$ \\
Alumina, $\mathrm{Al}_{2} \mathrm{O}_{3}$ & 765 & 3970 & 40 & $1 \times 10^{-10}$ \\
\hline
\end{tabular}




\subsection{Similarity Solutions}

The similarity transformations take the following form (Bhattacharyya and Vajravelu [30]):

$$
\eta=y\left(\frac{b}{2 v_{f} L}\right)^{1 / 2} \exp \left(\frac{x}{2 L}\right), \quad \theta(\eta)=\frac{T-T_{\infty}}{T_{w}(x)-T_{\infty}}, \quad \psi=\left(2 v_{f} L b\right)^{1 / 2} \exp \left(\frac{x}{2 L}\right) f(\eta)
$$

where $v_{f}, \eta$ and $\psi$ are the kinematic viscosity, similarity variable and stream function, while $f$ and $\theta$ is the dimensionless functions. Next, we defined $u=\partial \psi / \partial y$ and $v=-\partial \psi / \partial x$. Accordingly, Equation (1) is automatically satisfied.

We take $Q(x)=\frac{Q_{0}}{2 L} \exp (x / L)$ and $B=B_{0} \exp \left(\frac{x}{2 L}\right)$ where $Q_{0}$ denotes the heat source/sink coefficient and $B_{0}$ is the constant magnetic field in order for the similarity solutions to exist. Variables (5) are substituted into the governing Equations (2) and (3) to produce the following ODEs:

$$
\begin{gathered}
\frac{\mu_{h f} / \mu_{f}}{\rho_{h f} / \rho_{f}} f^{\prime \prime \prime}-2 f^{\prime 2}+f f^{\prime \prime}-\frac{\sigma_{h f} / \sigma_{f}}{\rho_{h f} / \rho_{f}} M\left(f^{\prime}-1\right)+2=0 \\
\frac{1}{\operatorname{Pr}} \frac{k_{h f} / k_{f}}{\left(\rho C_{p}\right)_{h f} /\left(\rho C_{p}\right)_{f}} \theta^{\prime \prime}+f \theta^{\prime}-f^{\prime} \theta+\frac{1}{\left(\rho C_{p}\right)_{h f} /\left(\rho C_{p}\right)_{f}} \beta \theta=0
\end{gathered}
$$

in which prime denotes the differentiation with respect to $\eta$. Further, $\operatorname{Pr}=v_{f}\left(\rho C_{p}\right)_{f} / k_{f}$ and $M=\frac{2 \sigma_{f} B_{0}^{2} L}{b \rho_{f}}$ refer to the Prandtl number and magnetic field parameter, while $\beta=$ $\frac{Q_{0}}{b\left(\rho C_{p}\right)_{f}}$ denotes the heat source/sink parameter where $\beta>0$ stands for heat generation (source) and $\beta<0$ refers to heat absorption (sink).

Subsequently, Equation (4) becomes:

$$
\theta(0)=1, \quad f^{\prime}(0)=\lambda, \quad f(0)=0 ; \quad \theta(\eta) \rightarrow 0, \quad f^{\prime}(\eta) \rightarrow 1 \quad \text { as } \quad \eta \rightarrow \infty
$$

Here, $\lambda=a / b$ is the stretching/shrinking parameter given that $\lambda<0$ and $\lambda>0$ denote the sheet is shrunk and stretch, respectively, $\lambda=0$ refers to a static sheet.

\subsection{Physical Quantities}

The skin friction $C_{f}$ and Nusselt number $N u_{x}$ are the physical quantities of interest in this research and can be described as:

$$
C_{f}=\frac{\mu_{h f}\left(\frac{\partial u}{\partial y}\right)_{y=0}}{\rho_{f} u_{e}^{2}}, \quad N u_{x}=-\frac{2 L k_{h f}\left(\frac{\partial T}{\partial y}\right)_{y=0}}{k_{f}\left(T_{w}-T_{\infty}\right)}
$$

By implementing the variables (5) into Equation (9), we have:

$$
C_{f} \operatorname{Re}_{x}^{1 / 2}=\frac{\mu_{h f}}{\mu_{f}} f^{\prime \prime}(0), \quad N u_{x} \operatorname{Re}_{x}^{-1 / 2}=-\frac{k_{h f}}{k_{f}} \theta^{\prime}(0)
$$

where $\operatorname{Re}_{x}=2 L u_{e} / v_{f}$ is the Reynolds number.

\section{Stability Analysis of Solutions}

The present investigation admits more than one solution for some range of governing parameters. As a result, a stability analysis is required. The first step is to consider the current problem as an unsteady problem as suggested by Merkin [35]. Therefore, Equation (1) remains the same while the unsteady governing equations is rewritten as: 


$$
\begin{aligned}
& \frac{\partial u}{\partial t}+u \frac{\partial u}{\partial x}+v \frac{\partial u}{\partial y}=u_{e} \frac{d u_{e}}{d x}+\frac{\mu_{h f}}{\rho_{h f}} \frac{\partial^{2} u}{\partial y^{2}}-\frac{\sigma_{h f}}{\rho_{h f}} B^{2}\left(u-u_{e}\right) \\
& \frac{\partial T}{\partial t}+u \frac{\partial T}{\partial x}+v \frac{\partial T}{\partial y}=\frac{k_{h f}}{\left(\rho C_{p}\right)_{h f}} \frac{\partial^{2} T}{\partial y^{2}}+\frac{Q(x)}{\left(\rho C_{p}\right)_{h f}}\left(T-T_{\infty}\right)
\end{aligned}
$$

subjected to the conditions (4). Next, a new dimensionless time variable $\tau$ is introduced:

$$
\tau=\frac{b}{2 L} t \exp \left(\frac{x}{L}\right)
$$

while the new dimensionless transformation can be rewritten as:

$$
\eta=y\left(\frac{b}{2 v_{f} L}\right)^{1 / 2} \exp \left(\frac{x}{2 L}\right), \quad \psi=\left(2 v_{f} L b\right)^{1 / 2} \exp \left(\frac{x}{2 L}\right) f(\eta, \tau), \quad \theta(\eta, \tau)=\frac{T-T_{\infty}}{T_{w}(x)-T_{\infty}}
$$

When the variables (13) and (14) are substituted into Equations (11) and (12), the obtained equations are:

$$
\begin{gathered}
\frac{\mu_{h f} / \mu_{f}}{\rho_{h f} / \rho_{f}} \frac{\partial^{3} f}{\partial \eta^{3}}-2\left(\frac{\partial f}{\partial \eta}\right)^{2}+f \frac{\partial^{2} f}{\partial \eta^{2}}+2-\frac{\sigma_{h f} / \sigma_{f}}{\rho_{h f} / \rho_{f}} M\left(\frac{\partial f}{\partial \eta}-1\right)-\frac{\partial^{2} f}{\partial \eta \partial \tau}+2 \tau\left(\frac{\partial f}{\partial \tau} \frac{\partial^{2} f}{\partial \eta^{2}}-\frac{\partial f}{\partial \eta} \frac{\partial^{2} f}{\eta \eta \partial \tau}\right)=0 \\
\frac{1}{\operatorname{Pr}} \frac{k_{h f} / k_{f}}{\left(\rho C_{p}\right)_{h f} /\left(\rho C_{p}\right)_{f}} \frac{\partial^{2} \theta}{\partial \eta^{2}}-\theta \frac{\partial f}{\partial \eta}+f \frac{\partial \theta}{\partial \eta}+\frac{\beta}{\left(\rho C_{p}\right)_{h f} /\left(\rho C_{p}\right)_{f}} \theta-\frac{\partial \theta}{\partial \tau}-2 \tau\left(\frac{\partial f}{\partial \eta} \frac{\partial \theta}{\partial \tau}-\frac{\partial f}{\partial \tau} \frac{\partial \theta}{\partial \eta}\right)=0
\end{gathered}
$$

and the transform conditions are:

$$
\begin{gathered}
f(0, \tau)+2 \tau \frac{\partial f}{\partial \tau}(0, \tau)=0, \quad \theta(0, \tau)=1, \quad \frac{\partial f}{\partial \eta}(0, \tau)=\lambda, \\
\theta(\eta, \tau) \rightarrow 0, \quad \frac{\partial f}{\partial \eta}(\eta, \tau) \rightarrow 1 \quad \text { as } \quad \eta \rightarrow \infty
\end{gathered}
$$

Afterwards, we write [36]:

$$
f(\eta, \tau)=f_{0}(\eta)+e^{-\gamma \tau} F(\eta, \tau), \quad \theta(\eta, \tau)=\theta_{0}(\eta)+e^{-\gamma \tau} H(\eta, \tau),
$$

for the purpose to specify the stability of the steady flow solution of $\theta(\eta)=\theta_{0}(\eta)$ and $f(\eta)=f_{0}(\eta)$. From the above equation, $F(\eta, \tau)$ and $H(\eta, \tau)$ are relatively smaller than $f_{0}(\eta)$ and $\theta_{0}(\eta)$, while $\gamma$ is the smallest eigenvalues parameter. Substitute Equation (18) into Equations (15)-(17) and setting $\tau=0$, we have $H(\eta)=H_{0}(\eta)$ and $F(\eta)=F_{0}(\eta)$. Therefore, the final linearized equations take the following form:

$$
\begin{gathered}
\frac{\mu_{h f} / \mu_{f}}{\rho_{h f} / \rho_{f}} F_{0}^{\prime \prime \prime}-4 f_{0}{ }^{\prime} F_{0}{ }^{\prime}+f_{0} F_{0}^{\prime \prime}+f_{0}^{\prime \prime} F_{0}-\frac{\sigma_{h f} / \sigma_{f}}{\rho_{h f} / \rho_{f}} M F_{0}^{\prime}+\gamma F_{0}^{\prime}=0 \\
\frac{1}{\operatorname{Pr} \frac{k_{h f} / k_{f}}{\left(\rho C_{p}\right)_{h f} /\left(\rho C_{p}\right)_{f}}} H_{0}^{\prime \prime}+f_{0} H_{0}{ }^{\prime}+F_{0} \theta_{0}{ }^{\prime}-F_{0}{ }^{\prime} \theta_{0}-H_{0} f_{0}{ }^{\prime}+\frac{\beta}{\left(\rho C_{p}\right)_{h f} /\left(\rho C_{p}\right)_{f}} H_{0}+\gamma H_{0}=0
\end{gathered}
$$

associated with conditions:

$$
H_{0}(0)=0, \quad F_{0}{ }^{\prime}(0)=0, \quad F_{0}(0)=0 ; \quad H_{0}(\eta) \rightarrow 0, \quad F_{0}{ }^{\prime}(\eta) \rightarrow 0 \quad \text { as } \quad \eta \rightarrow \infty
$$

To solve the above-linearized equations, we need to relax a boundary condition of $F_{0}^{\prime}(\eta) \rightarrow 0$ when $\eta \rightarrow \infty$ and replace it with a new boundary condition $F_{0}^{\prime \prime}(0)=1$ as advocated by Harris et al. [37]. This set of linearized equations will eventually display an infinite set of eigenvalues $\gamma_{1}<\gamma_{2}<\ldots<\gamma_{n}$.

\section{Results and Discussion}

With the help of Matlab's in-built function (i.e., bvp4c solver), the self-similar ODEs (6) and (7) associated with its conditions (8) are solved numerically. In this section, the Prandtl number is fixed to 6.2 which denotes water [43], and the nanoparticle volume fraction $\left(\varphi_{1}, \varphi_{2}\right)$ is varied from 0 to 0.2 . Further, we take $\beta=-0.2,-0.4,-0.6$ (for a heat sink), 
$\beta=0$ (without heat source/sink), $\beta=0.2,0.4,0.6$ (for the heat source) and magnetic parameter $M=0.1,0.2,0.3$.

\subsection{Validation of Results}

To validate the present model, we computed the outcomes as in Tables 3 and 4 for the skin friction coefficient $C_{f} \operatorname{Re}_{x}^{1 / 2}$ and local Nusselt number $N u_{x} \operatorname{Re}_{x}^{-1 / 2}$ when $\lambda=-0.5,0,0.5$. The results of our numerical calculation are in a good harmony with the results obtained from the work of Bachok et al. [31] when $M$ and $\beta$ are set to zero. Therefore, we are assured that the present code is true and this problem can be solved using the bvp4c solver.

Table 3. Comparison values of $C_{f} \operatorname{Re}_{x}^{1 / 2}$ for some values of $\lambda$ when $\varphi_{1}=0.1, \varphi_{2}=0$ and $M=0$.

\begin{tabular}{ccccccc}
\hline & \multicolumn{2}{c}{ Cu-Water } & \multicolumn{2}{c}{$\mathrm{Al}_{2} \mathbf{O}_{3}$-Water } & \multicolumn{2}{c}{ TiO $_{2}$-Water } \\
\cline { 2 - 7 }$\lambda$ & $\begin{array}{c}\text { Bachok } \\
\text { et al. [31] }\end{array}$ & Present & $\begin{array}{c}\text { Bachok } \\
\text { et al. [31] }\end{array}$ & Present & $\begin{array}{c}\text { Bachok } \\
\text { et al. [31] }\end{array}$ & Present \\
\hline-0.5 & 3.2381 & 3.238160 & 2.7531 & 2.753091 & 2.7827 & 2.782709 \\
0 & 2.5794 & 2.579342 & 2.1929 & 2.192963 & 2.2166 & 2.216555 \\
0.5 & 1.4682 & 1.468240 & 1.2483 & 1.248302 & 1.2618 & 1.261731 \\
\hline
\end{tabular}

Table 4. Comparison values of $N u_{x} \operatorname{Re}_{x}^{-1 / 2}$ for some values of $\lambda$ when $\varphi_{1}=0.1, \varphi_{2}=0$ and $\beta=0$.

\begin{tabular}{ccccccc}
\hline & \multicolumn{2}{c}{$\mathbf{C u}-$ Water } & \multicolumn{2}{c}{$\mathbf{A l}_{2} \mathbf{O}_{3}$-Water } & \multicolumn{2}{c}{ TiO $_{2}$-Water } \\
\cline { 2 - 7 }$\lambda$ & $\begin{array}{c}\text { Bachok } \\
\text { et al. [31] }\end{array}$ & Present & $\begin{array}{c}\text { Bachok } \\
\text { et al. [31] }\end{array}$ & Present & $\begin{array}{c}\text { Bachok } \\
\text { et al. [31] }\end{array}$ & Present \\
\hline-0.5 & 3.2381 & 3.238160 & 2.7531 & 2.753091 & 2.7827 & 2.782709 \\
0 & 2.5794 & 2.579342 & 2.1929 & 2.192963 & 2.2166 & 2.216555 \\
0.5 & 1.4682 & 1.468240 & 1.2483 & 1.248302 & 1.2618 & 1.261731 \\
\hline
\end{tabular}

\subsection{Interpretation of Results}

In Figures 2 and 3, numerical results for various nanoparticle volume fraction $\varphi_{1}$ and $\varphi_{2}$ for shrinking sheet $(\lambda=-1.2)$ are plotted for velocity $f^{\prime}(\eta)$ and temperature $\theta(\eta)$ profiles. Both figures are exemplified for 3 sets of nanoparticle volume fraction, i.e., $\varphi_{1}=$ $\varphi_{2}=0$ (Set 1), $\varphi_{1}=0.01, \varphi_{2}=0$ (Set 2) and $\varphi_{1}=\varphi_{2}=0.01$ (Set 3). Here, set 1 indicates the regular fluid, while sets 2 and 3 refer to ferrofluid $\left(\mathrm{Fe}_{3} \mathrm{O}_{4} /\right.$ water) and hybrid ferrofluid $\left(\mathrm{CoFe}_{2} \mathrm{O}_{4}-\mathrm{Fe}_{3} \mathrm{O}_{4}\right.$ /water), respectively. From these graphical results, the second and first solutions are displayed through the dashed line and solid line, respectively. From the figures, we observed that set 3 shows a thinner boundary layer thickness (momentum and thermal) for the first and second solutions than sets 1 and 2. The disparities of skin friction coefficient $C_{f} \operatorname{Re}_{x}^{1 / 2}$ and local Nusselt number $N u_{x} \operatorname{Re}_{x}^{-1 / 2}$ against stretching/shrinking parameter $\lambda$ for some values of $\mathrm{CoFe}_{2} \mathrm{O}_{4}$ nanoparticle volume fraction $\varphi_{2}$ are portrayed in Figures 4 and 5. It is observed from Equation (10) that $C_{f} \operatorname{Re}_{x}^{1 / 2}$ and $N u_{x} \operatorname{Re}_{x}^{-1 / 2}$ are directly associated with the dimensionless velocity gradient $f^{\prime \prime}(0)$ and temperature gradient $-\theta^{\prime}(0)$ at the wall, respectively. It is seen that these physical quantities of interest $\left(C_{f} \operatorname{Re}_{x}^{1 / 2}\right.$ and $N u_{x} \operatorname{Re}_{x}^{-1 / 2}$ ) enhance with an upsurge in the volume fraction of $\mathrm{CoFe}_{2} \mathrm{O}_{4}$ nanoparticle $\varphi_{2}$ for the first solution. However, we observed that the values of $C_{f} \operatorname{Re}_{x}^{1 / 2}$ and $N u_{x} \operatorname{Re}_{x}^{-1 / 2}$ decrease when stretching/shrinking parameter $\lambda$ near its critical value $\lambda_{c}$. The rise in the $C_{f} \mathrm{Re}_{x}^{1 / 2}$ is due to an increment in the nanoparticles colloidal suspension that enhanced the collision of nanoparticle dispersion of ferrofluid. An increase in the nanoparticles volume fraction may physically increase its synergistic effect which, consequently, improves the heat transfer rate. This demonstrates that cooling in hybrid ferrofluid is much faster, whereas cooling in ferrofluid flow may take longer. It can also be seen from Figures 4 and 5 that a non-unique solution (dual solutions) happens to exist for shrinking sheet $(\lambda<-1)$, unique (one) solution is observed when $-1 \leq \lambda \leq 1$ and no solution when $\lambda<\lambda_{c}$, i.e., boundary layer separation is bound to take place. It should be noted that 
$\lambda_{c}=-1.53463,-1.53634$ and -1.53818 are the respective critical values of $\varphi=0,0.01$ and 0.02 . Accordingly, we can deduce that nanoparticle volume fraction acts in postponing the boundary later separation.

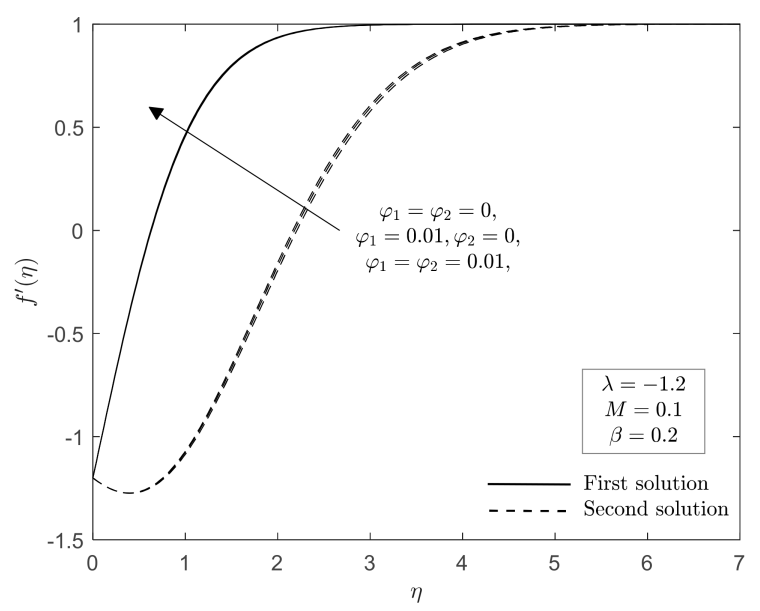

Figure 2. Velocity profile $f^{\prime}(\eta)$ for various value of $\varphi_{1}$ and $\varphi_{2}$ (Shrinking sheet case) when $M=0.1$ and $\beta=0.2$.

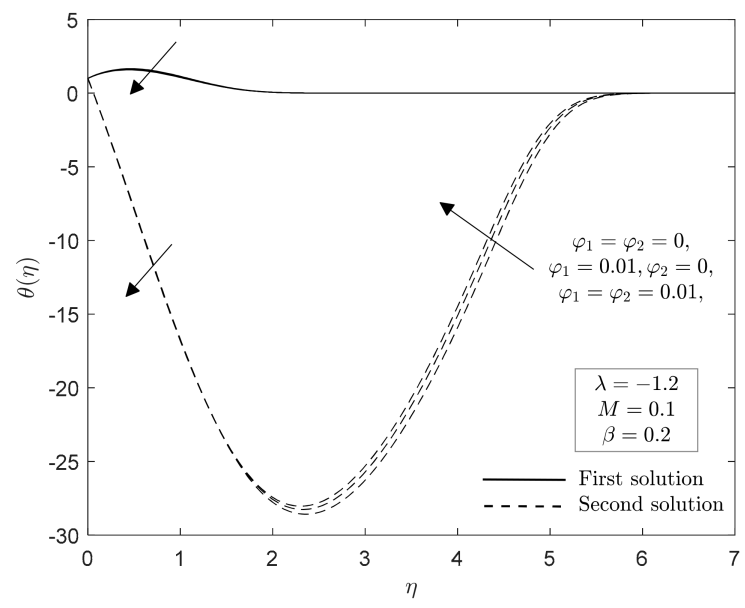

Figure 3. Temperature profile $\theta(\eta)$ for various values of $\varphi_{1}$ and $\varphi_{2}$ (Shrinking sheet case) when $M=0.1$ and $\beta=0.2$.

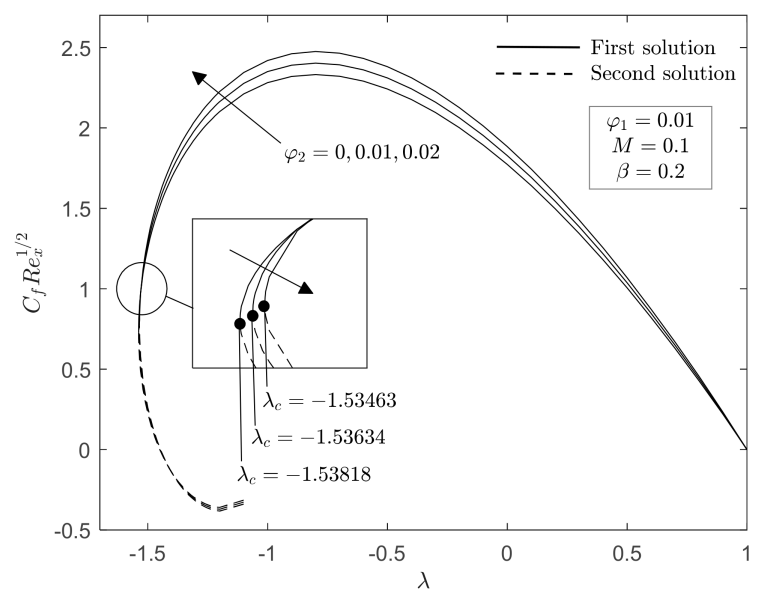

Figure 4. Skin friction coefficient $C_{f} \operatorname{Re}_{x}^{1 / 2}$ with $\lambda$ for some values of $\mathrm{CoFe}_{2} \mathrm{O}_{4}$ nanoparticle volume fraction $\varphi_{2}$ when $M=0.1$ and $\beta=0.2$. 


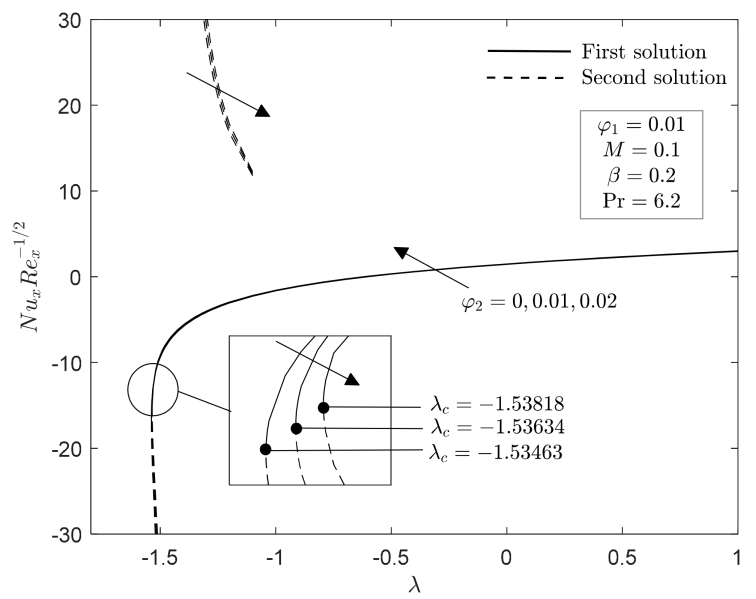

Figure 5. Local Nusselt number $N u_{x} \operatorname{Re}_{x}^{-1 / 2}$ with $\lambda$ for some values of $\mathrm{CoFe}_{2} \mathrm{O}_{4}$ nanoparticle volume fraction $\varphi_{2}$ when $M=0.1$ and $\beta=0.2$.

Figures 6 and 7 depict the graphical representation of the temperature profile $\theta(\eta)$ for selected values of heat source/sink parameter $\beta$. The influence of rising values of heat source $(\beta>0)$ is to increase the boundary layer thickness (thermal) for both solutions. As the heat source is increased, the temperature rises, thereby the sheet's temperature also increases. On the contrary, heat sink $(\beta<0)$ leads to decrement of the boundary layer (thermal) in first and second solutions. More heat is removed from the sheet as the heat sink increases, lowering the sheet's temperature. Furthermore, the temperature overshoot is observed for the second solution. This is in line with the fact that the dashed line which indicates the second solution always has a thicker boundary layer than the solid line, i.e., the first solution. The effect of heat source/sink $(\beta=-0.2,0,0.2)$ on the local Nusselt number $N u_{x} \operatorname{Re}_{x}^{-1 / 2}$ versus stretching/shrinking sheet $\lambda$ for hybrid ferrofluid is portrayed in Figure 8. One can see that as $\beta$ is increased, the temperature rises, which consequently lowers $N u_{x} \operatorname{Re}_{x}^{-1 / 2}$. Again, the appearance of the non-unique solution is discovered for the shrinking sheet $(\lambda<-1)$ only. In addition, for all heat source/sink parameter values $\beta$, the critical value $\lambda_{c}$ is the same, i.e., $\lambda_{c}=-1.53634$.

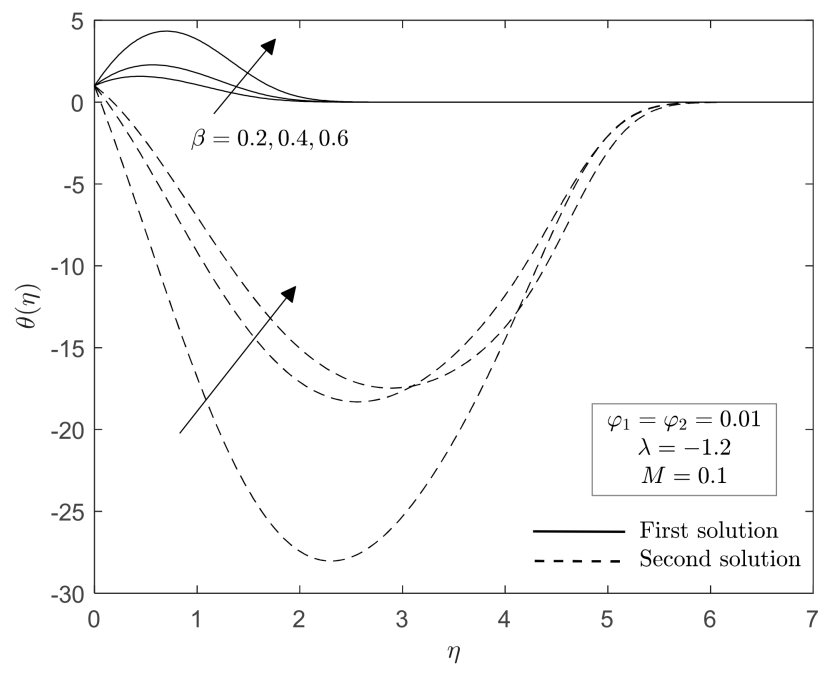

Figure 6. Temperature profile $\theta(\eta)$ for selected values of heat source $\beta$ (Shrinking sheet case) when $M=0.1$. 


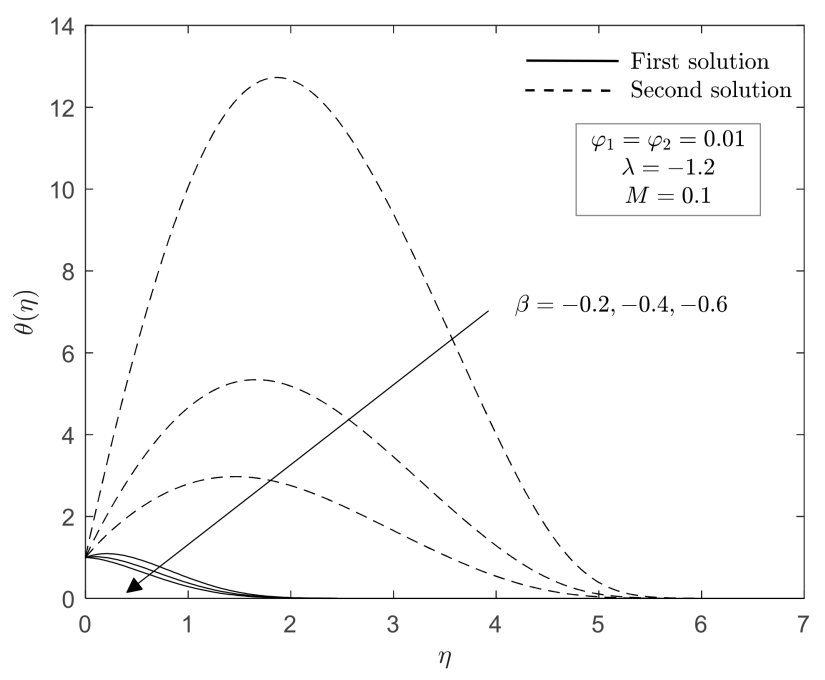

Figure 7. Temperature profile $\theta(\eta)$ for selected values of heat sink $\beta$ (Shrinking sheet case) when $M=0.1$.

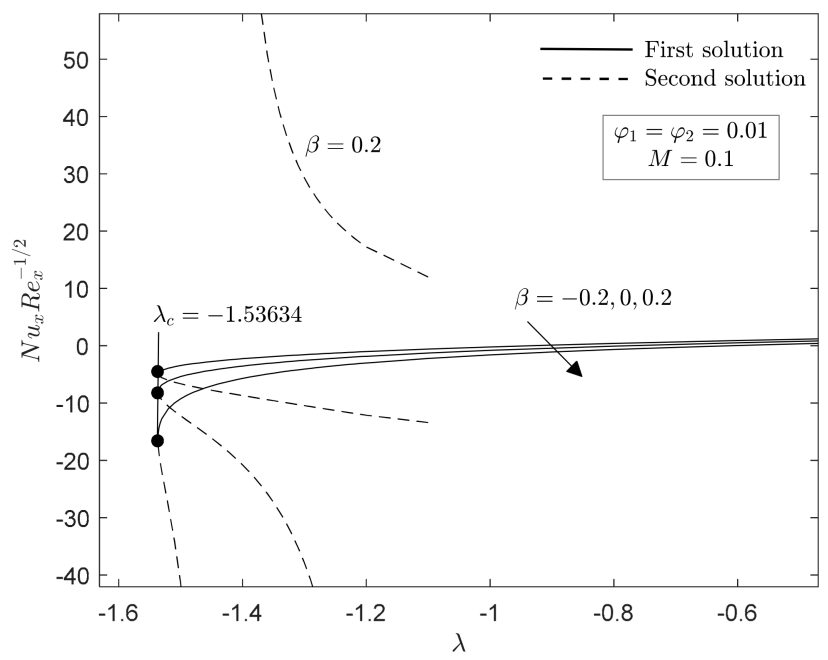

Figure 8. Local Nusselt number $N u_{x} \operatorname{Re}_{x}^{-1 / 2}$ with $\lambda$ for some values of heat source/sink $\beta$ when $M=0.1$.

The influence of magnetic parameter $M$ in the existence of heat source $(\beta=0.2)$ on the velocity $f^{\prime}(\eta)$ profile and temperature $\theta(\eta)$ profile are depicted in Figures 9 and 10, while skin friction coefficient $C_{f} \operatorname{Re}_{x}^{1 / 2}$ and local Nusselt number $N u_{x} \operatorname{Re}_{x}^{-1 / 2}$ are plotted in Figures 11 and 12, respectively. For accumulating amounts of magnetic parameter $M$, these profiles $\left(f^{\prime}(\eta)\right.$ and $\left.\theta(\eta)\right)$ significantly decrease and also cause the boundary layer thickness to reduce in the first solution. Nevertheless, an opposite observation is made for the other solution. The upsurge value of $M$ in the flow causes an increase in the Lorentz force or also known as resistive type force and consequently generates much more resistance to the flow and increases the temperature. Figures 11 and 12 for the skin friction coefficient $C_{f} \operatorname{Re}_{x}^{1 / 2}$ and local Nusselt number $N u_{x} \operatorname{Re}_{x}^{-1 / 2}$ demonstrate an increasing behavior for hybrid ferrofluid with an increasing magnetic parameter $M$. The influence of magnetic parameter $M$ on $N u_{x} \operatorname{Re}_{x}^{-1 / 2}$ is minimal as $M$ is not explicitly occurred in Equation (7). Again, the same observation is observed for the presence of dual solutions (see Figures 4,5 and 8). It is also clear from these graphs that as the magnetic parameter $M$ intensifies, the domain of the occurrence of dual solutions expands. For instance, the critical values of stretching/shrinking parameter for $M=0.1,0.2$ and 0.3 are $\lambda_{c}=-1.53634,-1.58568$ and -1.63506 . This implies that the presence of magnetic parameters can slow down the boundary layer separation to occur. 


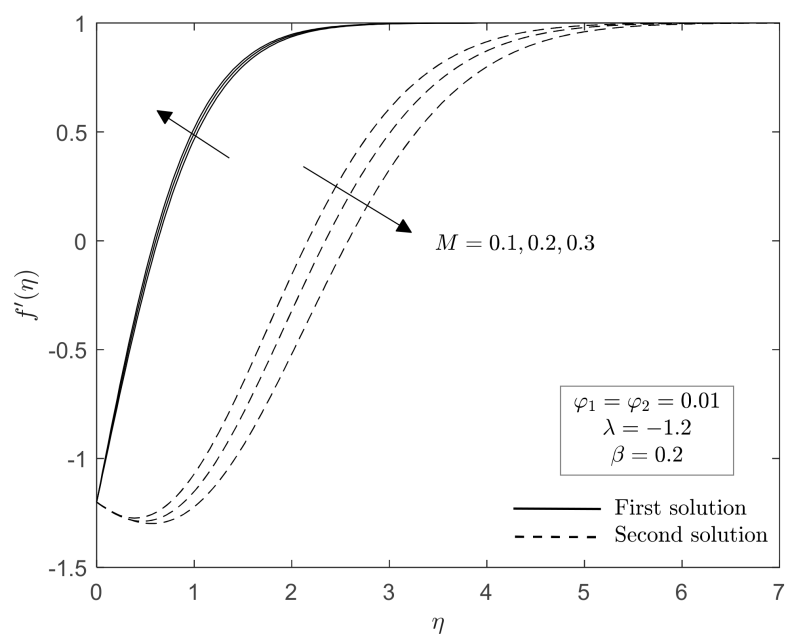

Figure 9. Velocity profile $f^{\prime}(\eta)$ for selected values of magnetic parameter $M$ (Shrinking sheet case) when $\beta=0.2$.

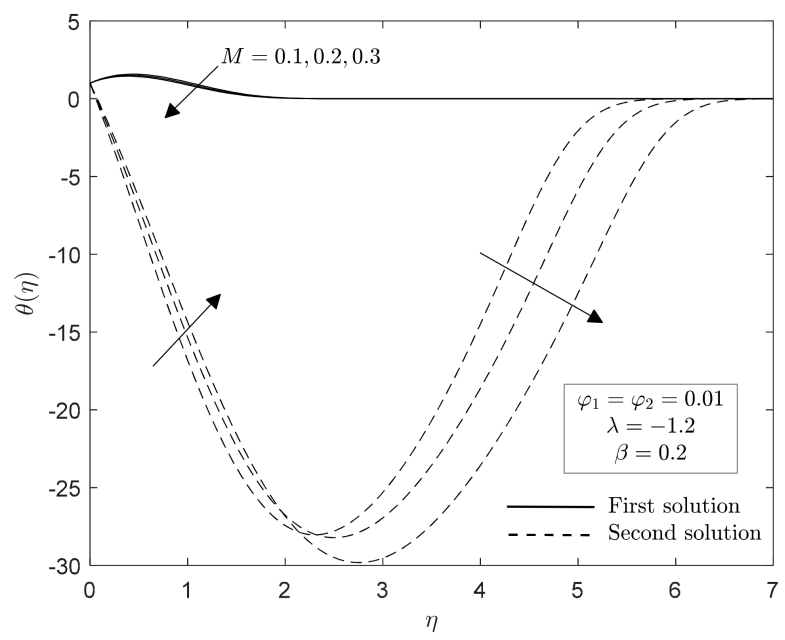

Figure 10. Temperature profile $\theta(\eta)$ for selected values of magnetic parameter $M$ (Shrinking sheet case) when $\beta=0.2$.

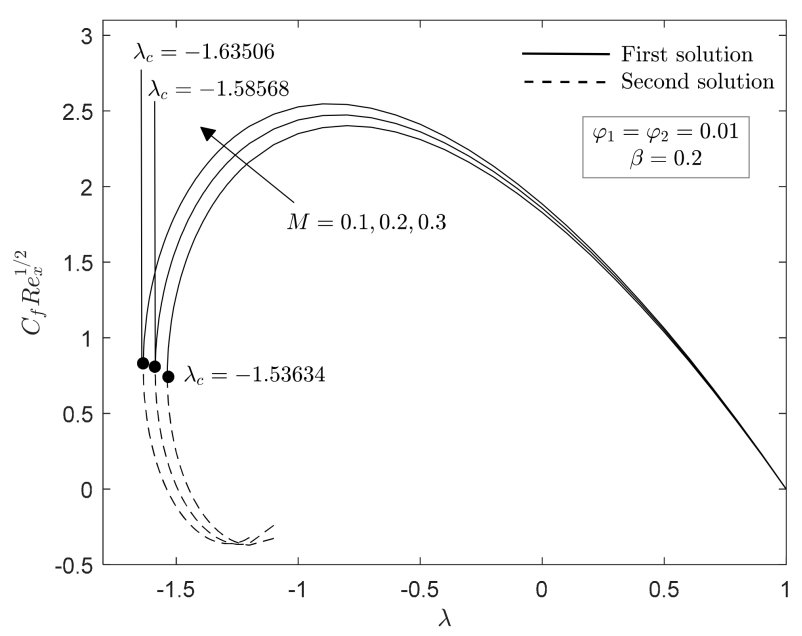

Figure 11. Skin friction coefficient $C_{f} \operatorname{Re}_{x}^{1 / 2}$ with $\lambda$ for selected values of magnetic parameter $M$ when $\beta=0.2$. 


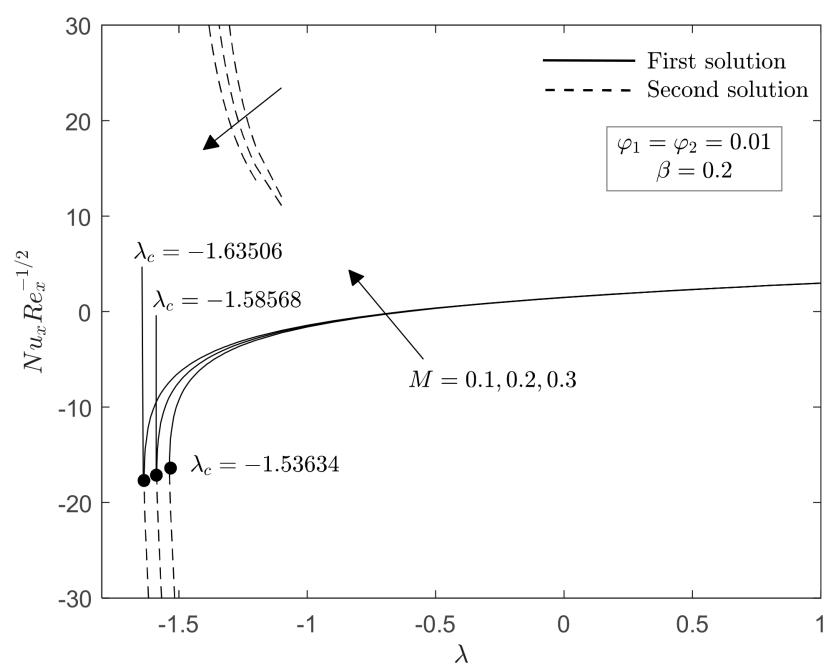

Figure 12. Local Nusselt number $N u_{x} \operatorname{Re}_{x}^{-1 / 2}$ with $\lambda$ for selected values of magnetic parameter $M$ when $\beta=0.2$.

The linearized Equations (19)-(21) are numerically solved using the same numerical approach as before in order to execute the stability of the solutions. To verify the stability of the solutions, a sign of the smallest eigenvalues $\gamma$ is essential. Hence, Figure 13 is plotted to demonstrate the behavior of the smallest eigenvalues $\gamma$ when $\beta=0.2$ and $M=0.1$ for hybrid ferrofluid $\left(\varphi_{1}=\varphi_{2}=0.01\right)$ concerning $\lambda$. Here, the positive eigenvalues indicate the stable solution (i.e., there is only a small disturbance that does not interrupt the flow) while negative eigenvalues convey the unstable solution (which explains the growth of disturbance). Therefore, it can be concluded from Figure 13 that the first solution is a stable solution and the other solution is not. In addition, it can be clearly seen that as stretching/shrinking parameter $\lambda$ near its critical value $\lambda_{c}$, the value of $\gamma$ also approximate to zero.

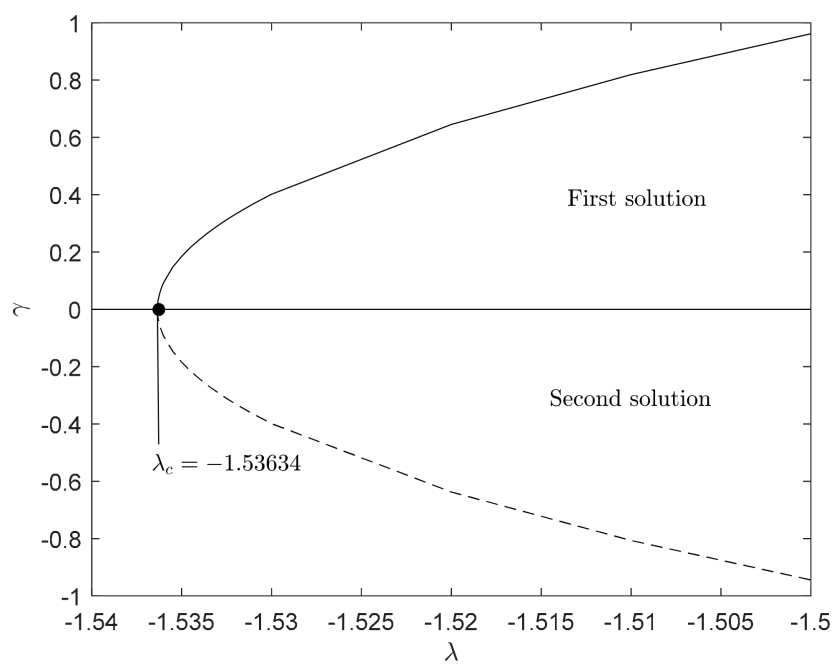

Figure 13. Smallest eigenvalues $\gamma$ with $\lambda$ when $\varphi_{1}=\varphi_{2}=0.01, \beta=0.2$ and $M=0.1$.

\section{Concluding Remarks}

The steady, stagnation point, MHD of hybrid ferrofluid flow caused by an exponentially deformable surface with heat source/sink effect is studied. The similarity transformation is applied to generate self-similar equations, which are then numerically solved with Matlab's built-in solver (bvp4c). The impact of governing parameters such as heat source/sink parameter, nanoparticle volume fraction, magnetic parameter and stretching/shrinking parameter are discussed in detail. We can therefore conclude that: 
- Non-unique solution (two solutions) occurs for a specific range of shrinking parameter $\left(\lambda_{c}<\lambda<-1\right)$, whereas one solution exists when $\lambda \geq-1$.

- The range of stretching/shrinking parameter $\lambda$ for which the non-unique solutions are in existence increased as magnetic parameter increase, while it decreased with an increase in $\mathrm{CoFe}_{2} \mathrm{O}_{4}$ nanoparticle volume fraction.

- The heat transfer and skin friction are escalated for increasing of $\mathrm{CoFe}_{2} \mathrm{O}_{4}$ nanoparticle volume fraction and magnetic parameter.

- When the heat source/sink parameter is increased, the surface temperature rises, and the local Nusselt number decreases.

- The first solution is confirmed to be a stable solution from the stability analysis test.

Author Contributions: Conceptualization, N.B. and I.P.; methodology, formal analysis and writing original draft preparation, N.S.A.; validation, N.S.A., N.B. and I.P.; writing-review and editing, supervision, N.B. and I.P.; funding acquisition, N.B. All authors have read and agreed to the published version of the manuscript.

Funding: This research was supported by the Fundamental Research Grant Scheme (FRGS) under Ministry of Higher Education with project number FRGS/1/2018/STG06/UPM/02/4.

Institutional Review Board Statement: Not applicable.

Informed Consent Statement: Not applicable.

Data Availability Statement: Not applicable.

Acknowledgments: The authors would like to express their gratitude to the anonymous reviewers for their valuable comments and suggestions for a betterment of this paper.

Conflicts of Interest: The authors declare no conflict of interest.

\section{References}

1. Rosensweig, R.E. Ferrohydrodynamics; Cambridge University Press: Cambridge, UK, 1985.

2. Ruuge, E.K.; Rusetski, A.N. Magnetic fluids as drug carriers: Targeted transport of drugs by a magnetic field. J. Magn. Magn. Mater. 1993, 122, 335-339. [CrossRef]

3. Goodwin, S.; Peterson, C.; Hoh, C.; Bittner, C. Targeting and retention of magnetic targeted carriers (MTCs) enhancing intraarterial chemotherapy. J. Magn. Magn. Mater. 1999, 194, 132-139. [CrossRef]

4. Scherer, C.; Figueiredo Neto, A.M. Ferrofluids: Properties and applications. Braz. J. Phys. 2005, 35, 718-727. [CrossRef]

5. Laroze, D.; Siddheshwar, P.G.; Pleiner, H. Chaotic convection in a ferrofluid. Commun. Nonlinear Sci. Numer. Simul. 2013, 18, 2436-2447. [CrossRef]

6. Abbas, Z.; Sheikh, M. Numerical study of homogeneous-heterogeneous reactions on stagnation point flow of ferrofluid with non-linear slip condition. Chin. J. Chem. Eng. 2017, 25, 11-17. [CrossRef]

7. Iqbal, M.S.; Malik, F.; Mustafa, I.; Ghaffari, A.; Riaz, A.; Nisar, K.S. Impact of induced magnetic field on thermal enhancement in gravity driven $\mathrm{Fe}_{3} \mathrm{O}_{4}$ ferrofluid flow through vertical non-isothermal surface. Results Phys. 2020, 19, 103472. [CrossRef]

8. Mehrez, Z.; El Cafsi, A. Heat exchange enhancement of ferrofluid flow into rectangular channel in the presence of a magnetic field. Appl. Math. Comput. 2021, 391, 125634. [CrossRef]

9. Takabi, B.; Salehi, S. Augmentation of the heat transfer performance of a sinusoidal corrugated enclosure by employing hybrid nanofluid. Adv. Mech. Eng. 2014, 6, 147059. [CrossRef]

10. Devi, S.A.; Devi, S.S.U. Numerical investigation of hydromagnetic hybrid $\mathrm{Cu}-\mathrm{Al}_{2} \mathrm{O}_{3} /$ water nanofluid flow over a permeable stretching sheet with suction. Int. J. Nonlinear Sci. Numer. Simul. 2016, 17, 249-257. [CrossRef]

11. Suresh, S.; Venkitaraj, K.P.; Selvakumar, P.; Chandrasekar, M. Synthesis of $\mathrm{Al}_{2} \mathrm{O}_{3}-\mathrm{Cu}$ /water hybrid nanofluids using two step method and its thermo physical properties. Colloids Surf. A Physicochem. Eng. Asp. 2011, 388, 41-48. [CrossRef]

12. Madhesh, D.; Kalaiselvam, S. Experimental analysis of hybrid nanofluid as a coolant. Procedia Eng. 2014, 97, 1667-1675. [CrossRef]

13. Esfe, M.H.; Arani, A.A.A.; Rezaie, M.; Yan, W.M.; Karimipour, A. Experimental determination of thermal conductivity and dynamic viscosity of Ag-MgO/water hybrid nanofluid. Int. Commun. Heat Mass Transf. 2015, 66, 189-195. [CrossRef]

14. Chu, Y.M.; Bilal, S.; Hajizadeh, M.R. Hybrid ferrofluid along with MWCNT for augmentation of thermal behavior of fluid during natural convection in a cavity. Math. Methods Appl. Sci. 2020, 2020, 1-12. [CrossRef]

15. Kumar, K.A.; Sandeep, N.; Sugunamma, V.; Animasaun, I.L. Effect of irregular heat source/sink on the radiative thin film flow of MHD hybrid ferrofluid. J. Therm. Anal. Calorim. 2020, 139, 2145-2153. [CrossRef]

16. Nabwey, H.A.; Mahdy, A. Transient flow of micropolar dusty hybrid nanofluid loaded with $\mathrm{Fe}_{3} \mathrm{O}_{4}-\mathrm{Ag}$ nanoparticles through a porous stretching sheet. Results Phys. 2021, 21, 103777. [CrossRef] 
17. Rashid, U.; Liang, H.; Ahmad, H.; Abbas, M.; Iqbal, A.; Hamed, Y.S. Study of $\left(\mathrm{Ag}\right.$ and $\left.\mathrm{TiO}_{2}\right) /$ water nanoparticles shape effect on heat transfer and hybrid nanofluid flow toward stretching shrinking horizontal cylinder. Results Phys. 2021, 21, 103812. [CrossRef]

18. Anuar, N.S.; Bachok, N.; Arifin, N.M.; Rosali, H. Analysis of $\mathrm{Al}_{2} \mathrm{O}_{3}-\mathrm{Cu}$ nanofluid flow behaviour over a permeable moving wedge with convective surface boundary conditions. J. King Saud Univ.-Sci. 2021, 33, 101370. [CrossRef]

19. Hayat, T.; Fetecau, C.; Sajid, M. Analytic solution for MHD transient rotating flow of a second-grade fluid in a porous space. Nonlinear Anal. Real World Appl. 2008, 9, 1619-1627. [CrossRef]

20. Kumar, D.; Singh, A.K.; Kumar, D. Influence of heat source/sink on MHD flow between vertical alternate conducting walls with Hall effect. Phys. A Stat. Mech. Appl. 2020, 544, 123562. [CrossRef]

21. Bhattacharyya, K. Effects of heat source/sink on MHD flow and heat transfer over a shrinking sheet with mass suction. Chem. Eng. Res. Bull. 2011, 15, 12-17. [CrossRef]

22. Gorla, R.S.R.; Siddiqa, S.; Mansour, M.A.; Rashad, A.M.; Salah, T. Heat source/sink effects on a hybrid nanofluid-filled porous cavity. J. Thermophys. Heat Transf. 2017, 31, 847-857. [CrossRef]

23. Armaghani, T.; Sadeghi, M.S.; Rashad, A.M.; Mansour, M.A.; Chamkha, A.J.; Dogonchi, A.S.; Nabwey, H.A. MHD mixed convection of localized heat source/sink in an $\mathrm{Al}_{2} \mathrm{O}_{3}-\mathrm{Cu}$ /water hybrid nanofluid in L-shaped cavity. Alex. Eng. J. 2021, 60, 2947-2962. [CrossRef]

24. Jamaludin, A.; Naganthran, K.; Nazar, R.; Pop, I. MHD mixed convection stagnation-point flow of $\mathrm{Cu}_{-} \mathrm{Al}_{2} \mathrm{O}_{3} /$ water hybrid nanofluid over a permeable stretching/shrinking surface with heat source/sink. Eur. J. Mech.-B/Fluids 2020, 84, 71-80. [CrossRef]

25. Reddy, N.N.; Rao, V.S.; Reddy, B.R. Chemical reaction impact on MHD natural convection flow through porous medium past an exponentially stretching sheet in presence of heat source/sink and viscous dissipation. Case Stud. Therm. Eng. 2021, 25, 100879. [CrossRef]

26. Wang, C.Y. Stagnation flow towards a shrinking sheet. Int. J. Non-Linear Mech. 2008, 43, 377-382. [CrossRef]

27. Bachok, N.; Ishak, A.; Pop, I. Stagnation-point flow over a stretching/shrinking sheet in a nanofluid. Nanoscale Res. Lett. 2011, 6 , 1-10. [CrossRef]

28. Kamal, F.; Zaimi, K.; Ishak, A.; Pop, I. Stability analysis on the stagnation-point flow and heat transfer over a permeable stretching/shrinking sheet with heat source effect. Int. J. Numer. Methods Heat Fluid Flow 2018, 28, 2650-2663. [CrossRef]

29. Anuar, N.S.; Bachok, N. Double solutions and stability analysis of micropolar hybrid nanofluid with thermal radiation impact on unsteady stagnation point flow. Mathematics 2021, 9, 276. [CrossRef]

30. Bhattacharyya, K.; Vajravelu, K. Stagnation-point flow and heat transfer over an exponentially shrinking sheet. Commun. Nonlinear Sci. Numer. Simul. 2012, 17, 2728-2734. [CrossRef]

31. Bachok, N.; Ishak, A.; Pop, I. Boundary layer stagnation-point flow and heat transfer over an exponentially stretching/shrinking sheet in a nanofluid. Int. J. Heat Mass Transf. 2012, 55, 8122-8128. [CrossRef]

32. Anuar, N.S.; Bachok, N.; Arifin, N.M.; Rosali, H. Stagnation point flow and heat transfer over an exponentially stretching/shrinking sheet in CNT with homogeneous-heterogeneous reaction: Stability analysis. Symmetry 2019, 11, 522. [CrossRef]

33. Lund, L.A.; Omar, Z.; Khan, I.; Baleanu, D.; Nisar, K.S. Dual similarity solutions of MHD stagnation point flow of Casson fluid with effect of thermal radiation and viscous dissipation: Stability analysis. Sci. Rep. 2020, 10, 1-13. [CrossRef] [PubMed]

34. Waini, I.; Ishak, A.; Pop, I. Hybrid nanofluid flow towards a stagnation point on an exponentially stretching/shrinking vertical sheet with buoyancy effects. Int. J. Numer. Methods Heat Fluid Flow 2020, 31, 216-235. [CrossRef]

35. Merkin, J.H. On dual solutions occurring in mixed convection in a porous medium. J. Eng. Math. 1986, 20, 171-179. [CrossRef]

36. Weidman, P.D.; Kubitschek, D.G.; Davis, A.M.J. The effect of transpiration on self-similar boundary layer flow over moving surfaces. Int. J. Eng. Sci. 2006, 44, 730-737. [CrossRef]

37. Harris, S.D.; Ingham, D.B.; Pop, I. Mixed convection boundary-layer flow near the stagnation point on a vertical surface in a porous medium: Brinkman model with slip. Transp. Porous Media 2009, 77, 267-285. [CrossRef]

38. Anuar, N.S.; Bachok, N.; Arifin, N.M.; Rosali, H. Numerical solution of stagnation point flow and heat transfer over a nonlinear stretching/shrinking sheet in hybrid nanofluid: Stability analysis. J. Adv. Res. Fluid Mech. Therm. Sci. 2020, 76, 85-98. [CrossRef]

39. Mustafa, I.; Abbas, Z.; Arif, A.; Javed, T.; Ghaffari, A. Stability analysis for multiple solutions of boundary layer flow towards a shrinking sheet: Analytical solution by using least square method. Phys. A Stat. Mech. Appl. 2020, 540, 123028. [CrossRef]

40. Aladdin, N.A.L.; Bachok, N.; Anuar, N.S. MHD stagnation point flow in nanofluid over shrinking surface using Buongiorno's model: A stability analysis. J. Adv. Res. Fluid Mech. Therm. Sci. 2020, 76, 12-24. [CrossRef]

41. Aladdin, N.A.L.; Bachok, N.; Pop, I. Boundary layer flow and heat transfer of Cu-Al2O3/water over a moving horizontal slender needle in presence of hydromagnetic and slip effects. Int. Commun. Heat Mass Transf. 2021, 123, 105213. [CrossRef]

42. Shampine, L.F.; Reichelt, M.W. The matlab ode suite. SIAM J. Sci. Comput. 1997, 18, 1-22. [CrossRef]

43. Oztop, H.F.; Abu-Nada, E. Numerical study of natural convection in partially heated rectangular enclosures filled with nanofluids. Int. J. Heat Fluid Flow 2008, 29, 1326-1336. [CrossRef]

44. Sheikholeslami, M.; Gorji-Bandpy, M.; Ganji, D.D. MHD free convection in an eccentric semi-annulus filled with nanofluid. J. Taiwan Inst. Chem. Eng. 2014, 45, 1204-1216. [CrossRef]

45. Tlili, I.; Mustafa, M.T.; Kumar, K.A.; Sandeep, N. Effect of asymmetrical heat rise/fall on the film flow of magnetohydrodynamic hybrid ferrofluid. Sci. Rep. 2020, 10, 6677. [CrossRef] 